\title{
Preparing for the Changing Faces of Education: Effective Professional Development Models
}

\author{
Yvonne DeWith
}

\begin{abstract}
The face of education is constantly changing. The traditional classroom with rows of desks facing a chalkboard is being demolished and replaced with movable tables, Smart Boards and laptops, project-based learning, differentiated lessons and more authentic assessment. To be effective and to accommodate a rapidly changing educational system, teachers must be trained and equipped. Regardless of the innovation or change, the process of traveling from a novice to an expert teacher is an ongoing journey which requires adequate training. The question remains as to what is the most effective method of moving teachers along the trajectory from novice to expert. Research has shown how ineffective single "one-off" workshops are at resulting in real change in a teacher's practice. Effective professional development to develop expertise in any area, however, should allow for sufficient time for practice, collaboration, self-reflection, and constructive feedback.
\end{abstract}

The importance of the teacher's role within the changing faces of education cannot be overlooked. As stated by Ememe, Aitokhuehi, Jegede and Ojo-Ajibare (2013), "education is a fundamental element of change and the pivot of development and the teacher is a major determinant of success or otherwise in the education sector" (p. 277). The teachers are crucial to bring about successful changes within the educational system. However, because "development is not static, and change is a continuous phenomenon, then, the knowledge needed to bring about change, or adapt to the change, in order to bring about the desired development cannot be static" (Ememe et al, 2013, p. 277). Since knowledge evolves as new concepts, issues and ideas arise, the ongoing professional development of teachers is imperative.

In his article, "Practical 4: Something for Curriculum Professors to Do" (1983), Schwab acknowledges the critical role of the teacher. In considering any curriculum changes or teaching practices, he gives two reasons why the teacher must be consulted. The first is that the teacher knows the children best.

The children of the school as learners: their behavior and misbehavior in classrooms: what they take as "fair" or "unfair" in the course of teaching-learning: what rouses hopes, fears, and despairs with respect to learning: what the children are inclined to learn: what they disdain and what they see as relevant to their present or future lives, are better known by no one than the teacher. It is he who tries to teach them. It is she who lives with them for the better part of the day and the better part of the year.

(Schwab, 1983, p. 245) 
The second reason for insisting that the teacher be consulted is that "teachers will not and cannot be merely told what to do" (p. 245). Furthermore, Schwab explains that:

Teachers are not, however, assembly line operators, and will not so behave. Further, they have no need, except in rare instances, to fall back on defiance as a way of not heeding. There are a thousand ingenious ways in which commands on what and how to teach can, will, and must be modified or circumvented in the actual moments of teaching. Teachers practise an art. Moments of choice of what to do, how to do it, with whom and at what pace, arise hundreds of times a school day, and arise differently every day and with every group of students. No command or instruction can be so formulated as to control that kind of artistic judgment and behavior, with its demand for frequent, instant choices of ways to meet an ever varying situation. Therefore, teachers must be involved in debate, deliberation, and decision about what and how to teach (Schwab, 1983, p. 245).

Within the field of education, questions surrounding professional development are numerous. Questions such as 'what constitutes professional development?'; 'what models of professional development are available?'; 'what makes one model more effective than others?' and 'who determines when and how often a teacher should participate in some form of professional development?' circulate amongst policy makers, administrators and educators. Each has their own agenda: policy makers see professional development as a means to introduce new innovations and shape the curriculum; administrators are concerned with the skill level of teachers; and the teachers focus on the practical nature of professional development and its direct relevance to classroom practice.

Even the term 'professional development' conjures up its own set of questions. Is further training through professional development required because of a teacher's lack of abilities or because of changes within the framework of education as a result of the ever-changing society in which we live? In other words, what is the purpose of professional development: to fix the teacher or to enlighten the teacher?

In considering the purpose to fix the teacher, the term 'professional development' implies a deficit in a teacher's abilities. Taylor describes how the 'black-box' approach to professional learning is "to find gaps in teachers' knowledge and practice and then upskill teachers in order to fill these gaps" (Taylor, 2013, p.10). This approach is based on a "deficit model of learning, which relies on an expert depositing knowledge into learners, who need to know" (p.10). Because the learning happens with little dialogue, teachers rely passively on others to transmit knowledge. Unfortunately, such an approach minimizes the intellectual capabilities of the teachers and assumes teachers need 'developing'. Instead of the term 'professional development,' a better term to use is 'professional learning'. 'Professional learning' recognizes the teachers' abilities and encourages ongoing learning through debate and problem solving (Taylor, 2013). The position of the learner changes from a "receiver of knowledge to active participant in its creation" (Taylor, 2013, p. 10). Furthermore, as teachers engage in the learning process, they are "finding new ways to think and be a teacher [which] creates energy and encourages teachers to experiment more in their teaching practice" (p.14). 
The purpose of professional development or professional learning is not to fix the teacher but to enlighten the teacher on educational changes. One such change is the role of education. Previously, the role of education was for teachers to transmit knowledge and for students to regurgitate facts. To ensure greater student achievement and increased student motivation, current research proposes a new mode of teaching that is more student centered and which includes project-based learning and experiential activities. The role of education is now to equip students with key competencies such as problem solving, critical thinking, inquiry, collaboration, and technological literacy (BC's Education Plan, 2013). The area of technology also demonstrates how education has changed over time. Blackboards, for example, have been replaced with Smart Boards, projectors and 1:1 device classrooms. Since education is not stagnant, teachers must keep apprised of the changes. In addition, because teachers are in positions of influence and have a huge impact on society as they mold and shape the lives of children, it is imperative for teachers to stay current in the field of education while striving to find creative ways to engage the next generation. In fact, the very strength of a country's educational system is determined by the quality of its teachers (Ememe, Aitokhuehi, Jegede and Ojo-Ajibare, 2013). So, if the purpose of professional development is to enlighten teachers, what is the best way to prepare teachers for changes in the educational system?

Traditionally, "the most widespread professional learning for teachers has been seminars and workshops; one-off events with universal content, targeted at a generic audience and focused on the technical or practical aspects of teaching" (Taylor, 2013, p.10). Such lectures and one-off workshops tend to be passive, decontextualized and devoid of collaboration with colleagues (Opfer \& Pedder, 2010). In addition, short term, one-off workshops are ineffective at bringing about real changes in teaching practice as there is no continuity, follow-up or ongoing feedback (Ememe, Aitokhuehi, Jegede and Ojo-Ajibare, 2013; Lydon \& King, 2009). Because of the ineffectiveness of such a model, "teachers are loathe to participate in anything that smacks of the one-day workshops offered by outside 'experts' who know (and care) little about the particular and specific contexts of a given school" (Lydon \& King, 2009, p. 66). The traditional model of professional development is no longer working. "Education reform," as stated by Psalla (2013), "will, thus, require teachers to rethink classroom practice and collaborate in ways they may have never before. In addition, there is a growing consensus that traditional forms of teacher development are inadequate for addressing teachers' issues and for confronting the challenges teachers face in their everyday practice" (p. 26). Clearly, a new model of professional development is needed.

The question then remains, 'what is an effective method of professional development that will encourage participation and result in the growth of a teacher's skills as an educator?' To delve into this further, one must first identify the qualities of effective professional development and then explore possible models that embody these qualities.

Professional development must be relevant to the classroom context. Opfer and Pedder (2010) recommend that professional development "needs to involve teachers in more active forms of learning with a clear link to classroom teaching and learning" (p. 
428). Ideally, to encourage real change in one's teaching practice, professional development should be continuous, long-term, and sustained (Opfer \& Pedder, 2010) and should be a constructive and supportive space that fosters teachers' drive to improve learning and instruction (Vetter, 2012). In his article, "The Practical 3: Translation into Curriculum," Schwab (1973) refers to the importance of coordinating five bodies of experience when devising new curriculum or deliberating changes in education. He reiterates the importance of the context in which the learning will take place. Understanding the milieus of the child, and in this case the teacher, is paramount to adapting to changes in education for the benefit of the children (Schwab, 1973).

Mielke and Frontier (2012) suggest "creating a system that helps teachers to generate continual, accurate feedback that can enable them to improve" (p. 13). It seems to be a consensus among researchers that "effective continuing professional development programs for teachers should therefore be a well-structured, wellcoordinated and detailed program that will focus on specific areas of need of the practicing teacher" (Ememe et al, 2013, p. 278). The content of the program should "include methods of teaching, student assessment, use of educational technology for instruction, co-operative learning in the classroom and in-depth study of the subject area among others" (p. 278).

Four models to deliver effective professional development that is sustained, collaborative, relevant and supportive will be considered. First, in reviewing Joyce and Shower's (1993 \& 1988) model of in-service training for teachers, as cited in Leblanc (1996), the authors identified a number of teacher training components that contribute to the transfer of knowledge or skills into actual classroom practice:

1. Presentation of theory or description of skill or strategy;

2. Modeling or demonstration of skills or models of teaching;

3. Practice in simulated and classroom settings;

4. Structured and open-ended feedback (provision of information about performance);

5. Coaching for application (hands on, in-class assistance with the transfer of skills and strategies in the classroom) (p. 27).

Through their study, the authors "concluded that for maximum effectiveness of most training activities, it would be wise to include several or all the components listed" (p. 27). As further cited in the literature,

...where continuous professional development is long term, further needs are met: critical friendship (sharing and building knowledge and skills in a supporting but challenging environment), 'vision' needs (being enabled to relate practice to theory), skill development needs, intellectual needs (e.g., engaging in systematic reading) and personal needs (increased self-esteem). (Lydon \& King, 2009, p. 65)

Second, DeSantis (2012) proposes a similar model that "should (1) build efficacy by scaffolding the instruction of new tasks, (2) establish long-term collaborative 
partnerships among teachers, and (3) include positive supervision that encourages teacher self-reflection and measures student engagement" (p. 51). He further argues that to build efficacy, the commonly used model of single workshop format leaves teachers without support as they attempt to add these newly acquired skills into their classroom instruction (p. 52). He states the importance of introducing concepts one at a time to increase a teacher's confidence while decreasing feelings of being overwhelmed (p. 52). According to DeSantis (2012), the key is to design professional development that allows for sustained, purposeful training while providing sufficient opportunities for selfreflection.

Third, Lydon and King (2009) highlight the relevance of the professional development. They suggest that the training must "provide new knowledge, ideas and skills relevant to the needs of the teacher [and be] delivered in a manner appropriate to the content, by a skilled practitioner" (p. 67). It is not enough for the content to be relevant; for maximum effectiveness, the training must be presented by someone who is keenly aware of the needs of the teachers. In addition, the best training occurs when innovations are supported by school management and when teachers have time and space away from the pressures of the classroom to experiment, reflect, and explore with colleagues (Lydon \& King, 2009).

Although each of the first three models has slight variations and emphasis, common elements emerge. When skills taught by an experienced presenter in small, manageable chunks in an atmosphere which values collaboration, self-reflection, practice time and constructive feedback, changes in the teacher's ability level and confidence occur. Additionally, effective professional development will result in a greater chance that the new innovation, technology or new curriculum will be adopted.

The fourth model to consider is action research. Action research also embodies the qualities suggested by the current literature for effective professional development, but tends to be more teacher-driven or teacher-initiated than the first three models. As demonstrated through research, change is most likely when it is initiated by the teacher in a 'bottom-up' approach, as opposed to required and demanded in a 'top-down' approach. Tyack and Cuban (1995), in Tinkering toward Utopia, reiterate that when educational reformers "focus on ways to improve instruction from the inside out rather than the top down" (p. 134) real change is implemented in the classroom.

Although action research initially became popular through the work of Lewin (as cited by Klein, 2012) "and his articulation of the action research process (planning, acting, observing, and reflecting) and Corey's seminal work that helped to mainstream action research into the field of education" (p.1), it is making a significant resurgence. The motivation for participating in action research is driven by teachers' desire to "improve the quality of teaching and learning as well as the conditions under which teachers and students work in schools" (Altricher, Feldman, Posch and Somekh, 2008, p.4). Action research is professional development that begins at the bottom-level: the teachers. It is recognized that the "practitioners are in the best position to engage in inquiry about their practice" (Klein, 2012, p.3). Because action research begins with the teachers, they feel a sense of ownership and pride as they seek to improve the quality of 
their own teaching. The sense of empowerment when teachers are given the opportunity to "objectively analyze and understand their own practice and have a clear vision of where they can improve" (Mielke \& Frontier, 2012, p. 13) is a powerful motivator for the adult learner to journey on the continuum towards expertise. The strategy within action research of "asking teachers what bothers them the most and to begin reforms there" (Tyack \& Cuban, 1995, p. 139) can be an effective vehicle for encouraging educational reform. In addition, because action research "is typically conducted in natural settings (schools, communities, and organizations) where a researcher is concerned about a particular issue of practice" (Klein, 2012, p. 3) the professional development is contextualized. Furthermore, action research "is intended to support teachers, and groups of teachers, in coping with the challenges and problems of practice and carrying through innovations in a reflective way" (Altricher, Feldman, Posch and Somekh, 2008, p.4). What makes this model of professional development unique is that

these teachers are 'normal' teachers who reflect on their practice to strengthen and develop its positive features. They are not prepared to accept blindly the problems they face from day to day, but instead they reflect upon them and search for solutions and improvements. They are committed to building on their strengths and to overcoming their weaknesses. They wish to experiment with new ideas and strategies, rather than letting their practice petrify (Altricher et al., 2008, p.4).

Action research is not a prescriptive method of techniques and "how-to's", but is characterized by a "continuing effort to closely interlink, relate and confront action and reflection, to reflect upon one's conscious and unconscious doings in order to develop one's actions, and to act reflectively in order to develop one's knowledge" (Altricher et al., 2008, p. 6).

This element of self-reflection, common in action research, is a critical element in developing one's skills. Unfortunately, self-reflection is often missing in many professional development experiences. One suggested tool for self-reflection is diary keeping. In Psalla's (2013) article, “Towards English teachers' professional development: Can self- and peer- observation help improve the quality of our teaching?", she describes how "diary keeping prompted the teacher to reflect on issues and concerns that were previously unarticulated or have never been carefully considered" (p.3o). Psalla described how diary keeping "illuminated the teacher's insights about her own teaching, fostered reflection on her own teaching practices and helped her uncover significant variables that would otherwise have gone unnoticed. The teacher diary documented her professional growth and her struggle to become a better educator (p.34). Simply thinking on one's teaching practices, however, will not bring about much real change in one's practice. As stated by Hamilton (2012), "there must also be purpose and subsequent action associated with reflection which includes deliberation as well as making choices and decisions about possible courses of action" (p. 46). This process of reflecting on what works in the classroom and why would be an excellent starting point to setting personal goals for one's own improvement. 
Self-reflection can be taken one step further to include peer collaboration. Reflection, in combination with "collegiality, collaboration and critical dialogue with peers" (Hamilton, 2012, p. 56) can be very beneficial in changing one's teaching and learning practices. This idea of constructive feedback or critical dialogue is another significant element often lacking in traditional modes of professional development. Although classroom observations were traditionally used for evaluative judgments of staff, they can become a useful method of stimulating growth in teachers. Previously, observations were conducted by administrators and were based on a prescribed list for the purpose of identifying what the teacher is doing right or wrong (Psalla, 2013). Peerobservations, on the other hand, can be an excellent method to provide valuable feedback. Following a case study of English teachers in Greece, Psalla noted that peer observations "provided [the participating teachers] with a richer understanding of teaching and enabled them to come up with more effective solutions to improve their classes" (Psalla, 2013, p.34). Psalla (2013) recommends that for maximum effectiveness, peer-observations should include a pre-observation and post-observation meeting between two teachers who welcome collaboration and have established a trusting, nonjudgmental relationship (p. 34).

The notion of peer to peer observations as a form of professional development is gaining popularity as researchers recognize the value of embedding professional development within the teacher's own school context. The difference in embedded professional development is the change in emphasis from an expert swooping in to 'develop' the teachers in a situation removed or extracted from their day-to-day context to one that "emphasizes localized professional learning opportunities...[that] exists in nested systems of schooling, contexts, and teaching" (Hamilton, 2012, p.43). Collaboration among colleagues within one's school is in direct contrast with traditional forms of professional development in which the 'expert' relays the information to a passive, unknowledgeable audience. The vertical lines of a hierarchy of knowledge are replaced with horizontal lines of communication among peers of equal status. As Schwab reiterates, "let us establish from the beginning the place of the scholarly member as only one among many and not the "first among peers"' (Schwab, 1973, p. 512). The status of the observer is that of an equal, as opposed to that of an authoritarian.

In one study conducted by Hamilton (2012), high school teachers were expected to set a goal for themselves and then choose three teachers to help meet this goal through peer observations. The process of setting goals was motivating and the time spent observing peers "enabled teachers to watch and learn from real-time, real-life teaching, unscripted and live learning from each other" (Hamilton, 2012, p. 51). In fact, "when a person identifies a specific goal and seeks out colleague experts connected to that goal, an observer may very well walk away from a peer observation with additional ideas and strategies they can apply in their own classroom" (p. 54). Joseph Schwab views this process of observation and evaluation as "an evaluation procedure in which the evaluator joins the experimental teacher in the classroom situation in which the materials are tested. Teacher and evaluator engage in an alert, sensitive watch to identify reactions and responses of children as they deal with the materials being evaluated, with a special eye for reactions and responses unanticipated in the stated 
intention" (Schwab, 1973, p. 513). In such a process, the opinions of both the evaluator and the experimental teacher are valid and deemed necessary. Although this sounds idyllic, Hamilton cautions that this model of peer to peer observation as the sole method of professional development is not without its limitations.

Hamilton (2012) describes the need for establishing a "long-term plan to develop and maintain teacher-learning communities' experiences" (p.56). Without such a plan, sustained ongoing collaboration between peers is unlikely due to the constraints of time and schedules. Another limitation of the peer to peer observation model stems from the participant's right to choose whom they will observe. In Hamilton's research study (2012), he found that some participants admitted "that they observed their friends and those colleagues with whom they were already familiar because it was comfortable and convenient" (p. 56) and not those from whom they would learn the most from. The model would need modifications "to encourage teachers to observe colleagues they do not know as well" and "to provide opportunities to observe colleagues who teach at the same times as their peers" (p.56).

Changes within the educational system are constant. According to his book, The Saber Tooth Curriculum (1939), Peddiwell reflects on the constancy of change in education. He strongly urges an ever-changing curriculum to meet the changing needs and demands of the community. He states that "it is to be supposed that all would have gone well forever with this good educational system if conditions of life in that community had remained forever the same" (Peddiwell, 1939, p. 33). Education is constantly changing and evolving as new research, innovations, technologies, issues and ideas come to light. "Change, however, is not easy; most people, including teachers, are afraid of change and tend to do things the way they always have" (Kurt, 2013, p. 568). To face these changes, stakeholders and policy makers must recognize that "welldesigned professional development is a powerful catalyst encouraging teacher change" (Noack, Mulholland and Warren, 2013, p. 450).

Providing support that is authentic, motivating and effective is critical to prepare teachers for the constant changes within education. It is imperative for schools to "foster an atmosphere that views "terms like practice, growth, improvement, learning, and effort as assets to embrace rather than as liabilities to avoid" (Mielke \& Frontier, 2012, p. 12). It is equally important for teachers to value the process of professional learning and to continuously seek opportunities for growth. Through various experiences, deliberate practice, peer observations, reflection and constructive feedback, teachers will be prepared to face the many changes in education. As a result of effective professional development, teachers need not be afraid of change but can revel in the excitement of how educational reforms and innovations will impact the next generation of students. 


\section{References}

Altricher, H., Feldman, A., Posch, P., \& Somekh, B. (2008). Teachers Investigate Their Work: An Introduction to Action Research Across the Professions. London: Routledge.

BC's Education Plan. (2013). Retrieved from http://www.bcedplan.ca/assets/pdf/bc edu plan.pdf

DeSantis, J. (2012). Getting the Most From Your Interactive Whiteboard Investment: Three Guiding Principles for Designing Effective Professional Development. Clearing House, 85(2), 51-55. doi: 10.1080/00098655.2011.607867

Ememe, P., Aitokhuehi, M., Jegede, S., \& Ojo-Ajibare, J. (2013). Enhancing Teaching Quality through Continuing Professional Education. European Journal Of Educational Studies, 5(2), 277-291.

Hamilton, E. (2013). His ideas are in my head: peer-to-peer teacher observations as professional development. Professional Development In Education, 39(1), 42-64. doi:10.1080/19415257.2012.726202

Joyce, B. \& Showers, B. (1988). Student Achievement through Staff Development. New York: Longman.

Kurt, S. (2013). Examining teachers' use of computer-based technologies: A case study. Education \& Information Technologies, 18(4), 557-570. doi:10.1007/s10639012-9199-7

Leblanc, P. (1996). Project Infusion: teachers, training, and technology. Journal of Information Technology for Teacher Education, (5)1-2, 25-34.

Lydon, S. \& King, C. (2009). "Can a single, short continuing professional development workshop cause change in the classroom?" Professional Development in Education, 35(1), 63-82. doi:10.1080/13674580802264746

Mielke, P. \& Frontier, T. (2012). Keeping Improvement in Mind. Educational Leadership, 70(3), 10-13.

Noack, M., Mulholland, J., \& Warren, E. (2013). Voices of reform from the classroom: teachers' approaches to change. Teachers \& Teaching, 19(4), 449-462. doi:10.1080/13540602.2013.770233

Peddiwell, J., (1939). The Saber-Tooth Curriculum...Including Other Lectures in the History of Paleolithic Education. New York: McGraw-Hill Book Company, Inc. 
Psalla, I. (2013). Towards English teachers' professional development: Can self- and peer- observation help improve the quality of our teaching?. Research Papers In Language Teaching \& Learning, 4(1), 25-43.

Rogers, E. (1995). Diffusion of Innovations (4 ${ }^{\text {th }}$ ed.). New York: The Free Press.

Schwab Joseph J. (August 1973). The Practical 3: Translation into Curriculum. School Review, 81, 501-522.

Schwab, J.J. (Autumn, 1983). The Practical 4: Something for Curriculum Professors to Do. Curriculum Inquiry, 13 (3), 245.

Taylor, L. (2013). Lived childhood experiences: Collective storytelling for teacher professional learning and social change. Australasian Journal Of Early Childhood, 38(3), 9-16.

Tyack, D., \& Cuban, L. (1995). Tinkering Toward Utopia, A Century of Public School Reform. Cambridge, Massachusetts: Harvard University Press.

Vetter, A. (2012). Teachers as Architects of Transformation: The Change Process of an Elementary-School Teacher in a Practitioner Research Group. Teacher Education Quarterly, 39(1), 27-49. 